\title{
Working space: gravity (Alfonso Cuarón) and the digital long take
}

Book or Report Section

Accepted Version

Purse, L. (2017) Working space: gravity (Alfonso Cuarón) and the digital long take. In: Pye, D. and Gibbs, J. (eds.) The Long Take: Critical Approaches. Palgrave Close Readings in Film and Television. Palgrave Macmillan, London, pp. 221-238. ISBN 9781137585721 Available at https://centaur.reading.ac.uk/77321/

It is advisable to refer to the publisher's version if you intend to cite from the work. See Guidance on citing.

Publisher: Palgrave Macmillan

All outputs in CentAUR are protected by Intellectual Property Rights law, including copyright law. Copyright and IPR is retained by the creators or other copyright holders. Terms and conditions for use of this material are defined in the End User Agreement.

\section{www.reading.ac.uk/centaur}

\section{CentAUR}

Central Archive at the University of Reading 
Reading's research outputs online 
Purse, L., 'Working Space: Gravity (Alfonso Cuarón) and the Digital Long Take.' In: Gibbs, J. and Pye, D. (eds), The Long Take: Critical Approaches, London: Palgrave Macmillan, 221-238, ISBN 9781137585721.

Computer generated images, digital compositing, and the move from the time-limited storage capacities of tape and celluloid to digital image capture, have provided the technological conditions for a return to the mobile long take in films as various as Russian Ark (Aleksandr Sokurov, 2002), Children of Men (Alfonso Cuarón, 2006), Atonement (Joe Wright, 2007), The Avengers (Joss Whedon, 2012), Birdman (Alejandro G. Iñárritu, 2014), and Victoria (Sebastian Schipper, 2015). Alongside speculation about the artistic drivers for this return, the digital nature of these sequence shots has prompted heated debate about the artistic and technical labour they represent, and about their aesthetic and epistemological contributions to the films within which they sit. Alfonso Cuarón's Gravity (2013) has become one site of this debate. Released to much fanfare in Digital 3D and IMAX 3D formats as well as in 2D, the film follows the travails of two astronauts working in Earth's orbit who are cast adrift after space debris smashes into their shuttle. With many shots ranging from 10 to 17 minutes in length, and featuring open-ended camera movement across a highly photorealistic and potentially infinite diegetic space, Gravity emphatically showcases key capabilities of the digital long take. As a result, Gravity is a pertinent case study through which to explore questions of labour, aesthetics and narrative, and to ask how we can value the mobile long take in the digital era.

\section{Labour and artifice in a digital world}

The digital long take is most frequently positioned in marketing and press discourse as an 'assertion of aesthetic distinction' (Udden, 2009, p.42) that seeks to frame the makers of the long take film as auteurs; able to bring their vision to the screen because they are in full command of the expressive and technological potential of contemporary digital cinema. In press responses to Gravity 'virtuosity' is a common descriptor, denoting feats of imagination and technological control so remarkable that they are difficult for writers to fathom or describe (Scott, 2013; Travers, 2013). Variety's Justin Chang explicitly positions Cuarón alongside other established auteurs of cinema: 'Somewhere,' he imagines, 
‘the spirits of Stanley Kubrick and Max Ophüls are looking down in admiration' (2013, n.p.). Yet the digital long take also has its critics. In a 2014 article, Brad Stevens comments,

I found myself distinctly unimpressed by the 'bravura' opening shots of Alfonso Cuarón's Gravity (2013) and Kenneth Branagh's The Magic Flute (2006), since I knew perfectly well that they were only playing without cuts thanks to CGI... The production conditions which once gave them their impact no longer exist (Stevens, 2014, n.p.).

Such production conditions include the length of a celluloid reel, 1,000 feet or roughly eleven minutes, and the difficulty of choreographing actors, crew, and large pieces of filmmaking equipment in real time across this duration. In valorising the labour of long take filmmaking in the analogue era, Stevens elides not just the challenges of designing and staging that still exist in the digital long take, but also the labour of the invisible legions of digital compositors and animators whose work goes into the construction of these extended sequence shots today. ${ }^{1}$ The long take still involves artistic and practical labour, and an investment in deploying duration (and often movement too) in a purposeful manner.

Stevens' conception of the digital image itself is revealing, prioritising its artifice and its loss of an indexical relation to the real: 'we will no longer believe we are seeing something which is, or could be, "real"' (2014, n.p.). One senses a narrow interpretation of André Bazin here, an unfavourable mapping of celluloid and digital cinema onto Bazin's distinction between 'true realism, which is a need to express the meaning of the world in its concrete aspects and in its essence, and the pseudorealism of trompe l'oeil (or trompe l'esprit), which is content with the illusion of form' (Bazin, [1945] 2009, p.6, 'Ontology of the Photographic Image'). Certainly Stevens seeks to categorise overtly digitally constructed long take films as 'content with the illusion of form' only. ${ }^{2} \mathrm{He}$ even suggests that digital images' lack of an indexical relation to the real world determines an inherent inability to engage with the real world. Discussing a long take from Vincente Minnelli's Lust for Life (1956) he opines, '[w]hereas Minnelli's sequence shots throw us back into the social world, those of the digital era insulate us from it' (2014, n.p.). Yet a filmmaking technology's capacity for realism does not lie with the technology itself, but with the filmmakers who take up that technology. 
Such criticisms of the digital long take are shaped by two factors. One is the cultural tendency to set the digital against the human, the result of a 'connotative network associated with digital media's cold sterility', which repeatedly links the digital to ideas of 'inhumanity, death, [and] the absence of warmth and vitality,' as André Gaudreault and Philippe Marion point out $(2015$, p. 75$){ }^{3}$ The other is a tendency to over-emphasise the index as the foundation of Bazin's conception of cinematic realism (see Morgan 2006; Gunning 2007). Daniel Morgan reminds us of Bazin's assertion of multiple realisms, that " $[\mathrm{t}]$ here is no one realism, but many realisms. Every era seeks its own, meaning the technology and aesthetic which can best record, hold onto and recreate whatever we wish to retain of reality' (Bazin, [1948] 2009, p. 52, 'William Wyler, the Jansenist of Mise en Scène’). Bazin's implication is that the realist filmmaker's ambition to address an aspect of the real world can be achieved through a range of styles (or realisms), from those that assert an indexical relation to the world, to those that involve a significant amount of stylisation. ${ }^{4}$ Thus, as Morgan suggests, the task becomes,

to discover, from looking at a film, what it is that its style is acknowledging [about the world] ... and whether that involves doing something with the knowledge of its ontological foundation (Morgan, 2006, p. 472).

This reading of Bazin permits the artifice of the digital image, as long as it is deployed in the service of expressing 'the meaning of the world in its concrete aspects and its essence' - which can designate social or political relations as much as indexical ones.

Given Bazin's appreciation of the long take's ability to 'bring out [the] deep structure' of reality, 'the pre-existing relations which make up the story' (Bazin, [1958] 2009, p. 91, 'The Evolution of Film Language'), the digital constructedness of Gravity has the power to be elevated to a 'realism' if its long takes reveal something of the real world as part of their revelation of the relations at work in the fictional world. ${ }^{5}$ In what follows I will suggest that Gravity achieves this through its use of movement over duration. Set against the digital long take's reputation for ease of movement, and in closer proximity to how the long take has been valued in the past, Gravity constructs a world in which 
movement through space takes time and effort. Movement must be lived through, experienced and costed, and the characters' narrative trajectories express and reflect on these costs. While popular responses to Gravity are marked by an extra-textual, celebratory discourse of the technological mastery of the auteur filmmaker, in which the film narrative is mostly a vehicle for cinematic spectacle, I want to focus on the diegetic treatment of the theme of movement and how it might speak of relations within and beyond the film. Contrasting the opening long take with one at the mid-point of the narrative, I will explore the film's refusal to take movement for granted, and suggest that it is here that Gravity's realist potential may be found.

\section{Labouring through space}

The opening long take introduces the orbital setting of the film, the key characters, and the precipitating crisis (the arrival of the satellite debris and its annihilation of the Explorer Space Shuttle). From the outset, the labour of moving through space is foregrounded thematically and literally. After a series of title cards accompanied by crescendoing minor chords that assert space as a hostile environment ('Life in space is impossible'), the first look at this environment appears benign and familiar: a static view of Earth from orbit, slowly rotating, its surface blues and greens garlanded with wisps of cloud. Duration and sound undergird the spectator's experiential awareness of the magnitude of this off-world expanse. At first, there is silence, then the distant sounds of radio communications, eventually intelligible as verbal updates between Houston Mission Control and astronauts conducting a spacewalk. During just under two minutes of radio reports and responses a space shuttle gradually comes into view, first a tiny speck in the far right-hand corner of the screen, then moving into closer views as it travels across the vista of Earth to the centre of the frame. The radio communications initially only touch the edge of audibility, forcing the spectator to strain to hear the far away chatter. As the shuttle slowly grows larger in the frame, the sounds slowly grow in volume, the gradual transition from barely audible to aurally close-by redoubling the spectator's sensory perception of the vastness of space and the labour of moving across it through the simulation of a physically oriented struggle for auditory cognition of objects at a distance (familiar to the Earthbound human; sound cannot travel in space, as the opening titles remind us). Additional visual cues 
further emphasise scale in this static framing: Earth dwarfs the diminutive vehicle to emphasise the difference in scale, and in 3D the floating stereo window is brought slightly into the audience space.

The labour of moving across space is initially folded into a narrative of progress, control and conquest that has traditionally characterised cultural discourses around space exploration (see Opt 1996), anchored here by the routine and good humoured radio transmissions between Houston and the astronauts, but more centrally by the visual familiarity of the Earth-from-orbit perspective. This view of Earth was only available to the layperson after the Apollo 17 mission brought back the famous 'Blue Marble' photograph in 1972, but has since become emblematic of space agencies' technological and scientific achievements, repeatedly returned to in documentaries, promotional videos and in fiction films and television programmes that curate the spectacular aspects of astronauts' mission footage and space visualisations. It is a rarefied travelogue image, observed from perhaps the last farflung aspirational destination. Gravity offers it in a series of digitally constructed and finessed vistas that frequently evoke the perspective of one of the characters, usually that of veteran astronaut Commander Matt Kowalski (George Clooney), though doing so without surrendering the ongoing trajectory of the long take. Despite his years of experience, Kowalski cannot help but exclaim more than once that 'you can't beat the view.' At these moments, when the camera reframes so that Earth fills the screen, the spectator's experience approximates the character's submission to this perceptual engulfment of the Earth from orbit, and the spectator is encouraged to appreciate the visual fruits of this successful conquest of space. The regularity with which the film moves into this appreciative perspective invites the spectator to approvingly contemplate not just the diegetic conquest of space, but also Gravity's technological 'conquest' of the image, with its intricate digital photorealism and its illusion of boundless movement. ${ }^{6}$

The experienced astronaut as awed spectator, and the digital spectacle of Earth that both he and the film contemplate, construct a 'technological sublime' that Scott Bukatman suggests is characteristic of post-1960s science fiction cinema (2003, p. 102). If the post-Kantian male subject contemplated the greatness of nature or the heavens in 'an imaginative experience in which the finitude of the body is 
left behind in the confrontation with infinity' (Battersby 2007, p. 123), in science fiction cinema that imaginative experience is one of a technologically produced 'artificial infinite' in which 'utopian fantasies of nature, kinetic power, spiritual truth, and human connection' allow the diegetic and extradiegetic viewer to manage the horror of a technological environment that 'has moved beyond our ability to control and cognize it' (Bukatman, 2003, p. 102-5). Bukatman points out that in science fiction cinema this 'artificial infinite' has often been frequently expressed through durational spectacles, such as Douglas Trumbull's special effects sequences for 2001: A Space Odyssey (1968) and Close Encounters of the Third Kind (1977) (ibid., p. 109). In these films, special effects sequences offer slow-moving, mobile long takes which present the technological sublime for detailed contemplation; as Bukatman points out, what results is a sense of incomprehensible or humandwarfing scale, but framed by a mobile camera whose spatial probing offers a reassuring mastery of that spectacle.

The digitally mediated contemporary world is today's manifestation of an overwhelming, accelerating, technologised environment, and in this digital era the reassuring mastery of the mobile camera becomes more emphatic. The advent of a virtual camera whose frame, path and environment can be computer generated or digitally combined with live action elements has prompted an expansion of the scale, complexity and duration of movement in long take films like Birdman, and mobile long take sequences like those in The Secret in Their Eyes (Juan José Campanella, 2009), Atonement and The Avengers. Drawing on the work of Giuliano Bruno (2002), Bruce Bennett argues that this contemporary trend for an endlessly and dynamically mobile viewpoint channels a touristic drive to map, penetrate, and exoticise that pertains not just to the subject matter created for our contemplation, but to the technological spectacle itself, just like in panoramas, travelogues, and IMAX presentations before it (Bennett, 2013). In this 'imperial visuality,' both diegetic space and its digital rendering is 'presented to the viewer as a novel, richly detailed visual field to scrutinise, navigate and consume,' the act of consumption producing a corresponding fantasy of unlimited mobility, access and visual mastery for the spectator to share (ibid., p. 2). 
Significantly it is Kowalski who is most closely associated with this mastering view, not simply in his contemplation of Earth, but in the pronounced mobility he is gifted through his jet-pack, which allows him to arc through the space around the shuttle without a tether. Kowalski and his jetpack appear as the shuttle grows larger in the frame, emerging from behind it in a slow sweep into the foreground of the shot while he also rotates laterally (see figure 1). His experience and relaxed state is expressed through these smooth multiple simultaneous rotations, and the fact that he is able to sustain a series of humorous anecdotes throughout, while soundtracking his spacewalk with a favourite Country \& Western playlist. ${ }^{7}$ Kowalski's command of the environment appears to trigger that of the camera; as he sweeps across the foreground of the erstwhile static Earth-view, the camera shifts left to keep him in frame and then tracks in to follow Kowalski's trajectory back towards the shuttle and behind it to reveal the Hubble Space Telescope being repaired by the two other astronauts in the open docking area, the camera mimicking his ease of movement with its own.

As the satellite moves into the foreground, Kowalski moves into the background of the frame, because the camera is now plotting its own exploratory path, smooth and rotating, picking up the mode of movement Kowalski has established. Touring the shuttle's environs, the camera continues the impression of playful perambulation begun by Kowalski, moving from one point of interest to another in a seemingly arbitrary manner. It is a mode of movement subsequently picked up, with some variation, by the other male astronaut, Shariff (played by Phaldut Sharma). Shariff, who comes into view as the camera moves closer to the Hubble telescope, has completed a difficult repair job (its difficulty signalled by applause from Mission Control), and celebrates by whooping, jigging and somersaulting away from Hubble, his tether bouncing him back towards his work area at regular intervals. Before the film clarifies that Kowalski is in command of this mission, the observant spectator might notice that the camera never follows Shariff, nor mimics his jigging movement. The Bollywood song Shariff sings, 'Mera joota hai Japani, ${ }^{8}$ is dismissed by Kowalski as 'some form of Macarena,' the white American's power to name (conferred diegetically by Mission Control, and extra-diegetically by the screenwriter) enacting an erasure of cultural specificity that positions Kowalski at the top of the character hierarchy at this point in the film. ${ }^{9}$ In technological terms, 
Shariff's jigging, a spatially contained form of physical self-expression located in the body, contrasts with Kowalski's technologically assisted expansive movements across space, which Kowalski himself links to a popular form of human transportation. 'This jet pack is one fine piece of thrust,' he comments, but 'I still prefer my '67 Corvette.' The choice of words conflates the combustion engine ('thrust') with a macho sexual innuendo that is normally deployed to sexualise and commodify the female body (as in, 'a fine piece of ass'). The effervescent motions displayed by the male astronauts and the camera in this section redouble the sense of this extensive space as a site for play, exploration, mapping, and mastery, but only, it seems, for the male astronauts. The movement of the camera, in combination with dialogue, delineates distinctions between the astronauts at the intersection of command hierarchy, technology, race and gender.

In the first visual encounter with Stone, her static positioning and her preference for stasis contrasts with both men's intense mobility. Rather than somersaulting or jetting around, the aptly named Stone is anchored at the end of the shuttle's immobile manipulator arm (see figure 2). A slowly spiralling camera pushes in towards her position, the movement of the frame underscoring her relative stillness. Her radio exchanges with Mission Control have already revealed that she experiences movement in zero gravity not in terms of freedom but as a physiological problem - of 'keeping your lunch down'. Bullock's vocal performance underscores this idea: laboured breathing, clearing of the throat and groans and gasps accompanying physical flinches, express Stone's discomfort and fear. The sound design further amplifies the effect: even simple actions (hooking up a tether, moving a faulty transmission card) create audible vibrations transmitted through Stone's space suit, manifesting as deep, muted, rumbles that are likely (not least in a theatre with surround sound) to unsettle the spectator in a directly physical way. Stone is here defined by her literal motion sickness, and an attitude to space in which spatially extensive movement is to be feared and avoided. The opening long take suggests that Stone will be excluded from the optical and motile command Kowalski already possesses; excluded, to return to my earlier invocation of the sublime, from the capacity for transcendence that dominant traditions have historically gifted the male subject but failed to extend to women (Yaeger, 1989; Battersby, 2007). 
Yet the relaxed proficiency of the male astronauts and the conquest narrative they represent is already, in the first encounter with Stone, being called into question by the very mobile camera strategies that would normally convey the 'imperial visuality' Bennett describes. As the camera homes in on Stone repairing the Hubble transmission card, it struggles to adopt a stable or fully controlled position or path in relation to Stone, constantly having to re-position itself as the momentum of its current rotation pulls the frame away from her. The arbitrariness of the camera's continuous motion no longer registers as playful, but feels laborious: the camera is, in fact, beginning to display the attributes of an object or camera person, sharing the diegetic space with the characters and subject to the same Newtonian laws. Animation Supervisor David Shirk notes that Cuarón 'wanted it to feel like there was a human hand on the camera,' creating 'an underwater handheld feel, where in scenes of rapid motion the camera operator would react and follow the action to hold frame, but we'd feel the effort of the operator controlling the camera mass' (Fordham, 136, p. 51). Here the nature of the camera's motion doesn't just convey the weightlessness of space, with its potential for playful movement; it also progressively foregrounds the difficulty of human orientation in that space, the struggle to control one's own motion, roll and direction of travel in zero gravity. The connotations of the camera's movement have subtly begun to shift away from a notion of mastery, towards something less certain.

\section{Vision and Touch}

Towards the end of this first long take the orbiting space debris hits the space shuttle in what Mission Control calls a 'rapidly expanding' and 'out of control' chain reaction, killing Shariff and dislodging Stone from the shuttle structure, sending her spiralling into space so fast that Kowalski is unable to follow. The sudden unmooring of Stone, and her enforced, spinning trajectory away from human assistance or any form of stabilising structure, has a strong sensory impact: the contrast with Kowalski's playful perambulation just minutes before is horrifying. But what gives the contrast its unique force is not simply the heightened sense of the spatial reach into which Stone has been flung (accumulated over the early part of this opening long take): the spectator is aligned with Stone's traumatised flailing state because the speed and trajectory she is being forced to travel is so clearly at 
odds with her established preference for anchored stillness. The debris precipitates a crisis of orientation for Stone, her attempts to re-orient herself and assert control over her trajectory in the hostile vastness of space staged across the narrative. But it also precipitates a crisis of the technological and the visual that affects Kowalski and Mission Control: satellite communications are down, space technologies cannot resist the debris or protect their human users; sight itself is no longer sufficient (witness Kowalski exclaiming in horror, 'Houston I've lost visual of Dr Stone!'). In this opening long take, camera movement has at first established visual and technological mastery in normative terms, but as the sequence shot develops, other connotations of movement come into view and come to be felt by the spectator. Here, and elsewhere in this film, long takes will invite the spectator to reconsider ways of being in and moving through the world and, specifically, to reconsider the conception of knowledge and control that the opening initially prioritises: optical mastery and engine-powered spatial penetration.

The remainder of the film will insist, again and again, on the impossibility of an all-seeing perspective. As Stone labours from the Explorer shuttle to the International Space Station (ISS), to a Soyuz space capsule, to the Chinese space station Tiangong-1, and finally to the Shenzou space capsule, vision is repeatedly revealed as insufficient. A clear view cannot save Kowalski, forced to cut his tether to Stone and sacrifice himself so that Stone is not pulled away from the ISS with him; Stone fails to see the sparking of a fire on the ISS which will force her to decamp to Tiangong-1; the Shenzou capsule's Chinese control labels cannot be easily read, forcing Stone to experiment in order to initiate re-entry protocols as the craft enters the Earth's atmosphere. At the same time, the long takes gradually reframe knowledge in terms of touch rather than vision. As Stone begins to reconcile herself to the spatially extensive trajectories she has been forced to travel, the spectator is also invited to forego the mastering view in favour of a more intimate, and more tactile, orientation.

A long take roughly half way through the movie illustrates how the film manages this transition. Stone has made it to the Soyuz escape pod on the International Space Station but the Soyuz parachute is tangled in the ISS's structure, so Stone needs to disengage the cord in order to escape, necessitating a 
space walk. The wide shot that starts the sequence uses planar composition and positive parallax to map out a deep, extensive space of action, with the various sections of the ISS spread out along the middle ground and the star field pricking the darkness in the far distance. The spectator is already alert to the dangers of such deep spaces, and, just like in the opening long take, a move from silence to slowly emerging sounds prompts the spectator to listen out for anything that might indicate a problem. The non-diegetic score's tense refrain of low, rolling chords is a reminder that every minute Stone is engaged in the task is a minute closer to the return of the orbiting satellite debris. But the camera's track in seems to discount these fears; Stone is humming to herself to maintain her composure, her heavy breathing signalling physical exertion rather than panic. The only other sounds are the contacts between Stone and the parachute cord, the cord and the Soyuz capsule, transmitted through her space suit. The camera smoothly pushes forward from the wide shot into a close-up, revealing Stone's face as she offers a Kowalski-like joke ('Clear skies with a chance of satellite debris') before calmly beginning to unscrew the bolts connecting the tangled parachute cord to the Soyuz. She is tethered but sufficiently composed to willingly float away from the Soyuz structure to re-position herself, an indication of the psychological distance she has travelled from her anxious 'paralysis' at the beginning of the film.

The International Space Station is relegated to a backdrop as close-ups and medium close-ups invite the spectator to focus on Stone's work in the foreground. Despite a highly mobile, circling camera, the task is staged across a lateral plane that consistently corresponds to the likely path of the returning debris field. This lateral plane is marked out first by Stone's own looks left and right to check for signs of the debris, and subsequently by Stone's positioning of the screwdriver at a $90^{\circ}$ angle to the exterior wall of the Soyuz (see figure 3). As the mobile camera positions itself just in front of Stone, her lateral efforts settle onto the x-axis; as Stone pushes the screwdriver into place, the spectator becomes invested in this lateral trajectory of physical purpose. Stone successfully disengages the first cord attachment, but her screwdriver begins to float away and in stretching out to grab it, she catches sight of what she has been dreading - the arrival of the debris field. Now Stone must concentrate even more to free the last of the parachute cord, as ever increasing quantities of debris rain across the 
lateral plane. Once again the spectator is invited to absorb themselves in Stone's laterally directly efforts, imaginatively pushing with her along this lateral trajectory, transfixed by her attempt to detach the final section of cord while the debris threatens around her.

Suddenly ricocheting debris causes the space station to explosively disintegrate, hurling objects towards Stone and straight at the camera. While focussed on Stone's efforts in the foreground of the shot, the spectator's sense of the extensive depth of the diegetic space had been suppressed. But the unexpected shift to the z-axis asserts a new trajectory for the action, the spectator's consciousness of the depth of the image opening outwards (switched 'back on') out without warning, disconcertingly and disturbingly, as if one were suddenly staring into an abyss (see figure 4). The scene's deep extension backwards is now marked out with a thousand pieces of debris. The Soyuz escape pod is knocked into a spiralling rotation, the camera 'locked' to its motion so that it continuously reframes to bring more of the disintegrating structures into view, and more debris explosions along the z-axis straight at the camera. The camera pulls backwards, Stone reduced to a small figure in the middle distance, managing to hold on while buffeted this way and that, until the expanding field of destruction falls away along the z-axis, a final visual pull towards the abyss of space.

This moment of forced reorientation for the spectator draws its power from the deployment of narrative absorption — we might even call it misdirection — accumulated along a lateral trajectory over time, and the suddenness of the shift from the x- to the z-axis that follows it. One could propose that the purpose of this shock is to align the spectator with Stone's own subjective experience of this sudden increase in the danger of her task. Yet the spectator's abrupt dislocation from the lateral plane contrasts sharply with Stone's newfound composure, from the humming that steadies her nerves even as the debris field arrives, to her gutsy hanging on as the Soyuz is knocked around by the larger structures collapsing around it. Stone is beginning to display the physical and mental skills she will need to exert more control over her trajectory, to get back home, but the spectator is not invited to share her self-possession, the camera recoiling and tracking this way and that for new threats in a way that Stone does not. The sensory shock for the spectator also makes a broader point, that the mastering 
view celebrated in the establishing 'shot' with which this long take begins is no guarantee of mastery. If Gravity's marketing drive invokes a touristic 'imperial visuality' and the promise of a mastering view of Earth, then the film itself is much more interested in disorientation, and the impossibility of a controlled or overarching perspective. As the film progresses Ryan gains composure, agency, and selfbelief, but significantly without recourse to a clear view. In the escape pods she must navigate using opaque porthole windows, which give little useful data, and on her final descent to Earth's surface the window is quickly blocked by the burn of the atmosphere, so that she is essentially flying blind. In response Stone adapts, foregoing the complacent relationship with technology and vision that Kowalski initially embodies, and re-purposing old technologies (the ageing space capsules, the fire extinguisher) to move forward.

In place of sight, touch becomes the privileged sense; trajectories are controlled and moorings acquired through fingertip touches, propelling hand pushes, and pressed computer control buttons, and, at the end of the film, the grasping of and steadying against the Earth itself. It is a compelling narrative arc for a bereaved character who has isolated herself from human interaction. Yet the film may also be seeking to say something more about the world to which Gravity refers: a world of technological advancement and striving, but often disconnected, beings. The digital constructedness of Gravity functions not just as a marketing draw and a way to intensify the film's ruminations on the technological sublime. The spiralling rhetoric of the camera's movements marks out a computer generated environment that surrounds both the characters and the spectator, an anxious space where control is promised but never quite possible; a metaphor, I suggest, for the enveloping character, and enveloping promises, of today's digital media environment. The longstanding cultural emphasis on the digital as artifice, as inhuman, masks the extent to which our lives are implicated in and lived through a range of digital touch points, from laptop keyboard to mobile touch screens to the novelty of repeating alerts and screen refreshes. As Thomas Elsaesser points out, '[e]mbedding in layered spaces, navigating mutable temporalities, and interacting with data-rich, simulated, and hybrid environments probably requires redefining what we mean by seeing' (2013, p. 235). No less importantly, this digital environment is characterised by invisible forces (algorithmic data, access and 
attention management) that suppress individual agency in favour of corporate control. Gravity speaks to this context through the totalising nature of its own digital environment, its ambivalent relationship to anchoring and control, and its long takes' prioritisation of touch over vision. Gravity is, then, not only a digital film keen to celebrate the importance of corporeal touch; it is more sensibly characterised as an attempt to think through the materiality, and power relations, that define our digitally mediated world, and the cyclical dramas of agency, lost and found, that define it.

\section{Notes}

${ }^{1}$ Such erasures are part of the wider devaluing of visual effects workers' labour in contemporary postproduction. See Venkatasawmy (2016).

${ }^{2}$ Perhaps he is subconsciously equating Bazin's use of the term 'trompe l'oeil' with the digital's capacity for fine-grained photorealism, which he reads only in terms of a loss of indexicality.

${ }^{3}$ Here Gaudreault and Marion draw upon the work of Jean-Philippe Tessé (2011).

${ }^{4}$ Morgan cites Bazin's work on Jean Renoir, in which he says 'Given the fact that this moment toward the real can take a thousand different routes... the movement is valuable only insofar as it brings increased meaning (itself an abstraction) to what is created' (cited in Morgan, 2006, p. 85).

${ }^{5}$ Bazin is discussing F.W. Murnau's long takes in Sunrise (1927) and Nosferatu (1922), suggesting that 'the composition adds nothing to reality and does nothing to distort it. On the contrary, it seeks to bring out its deep structure, the pre-existing relations which make up the story.' Morgan suggests that 'reality' is here is the physical reality of the fictional world: 'Bazin's conception of realism opens up the wide range of ways in which physical reality is caught up in and mixed with rational, discursive, and spiritual facts (and the styles that generate them)' (2006, p. 475). 


\footnotetext{
${ }^{6}$ Kowalski's sentiments are picked up by the director in promotional interviews, and echoed by critics - Richard Corliss for example, ended his thesis that 'Gravity shows us the glory of cinema's future' by enthusing that 'you truly can't beat the view' (2013). Joe Morgenstern of The Wall Street Journal went further, suggesting 'It's an experience none of us could have dreamed of until now', while Tom Huddleston exclaimed in Time Out London, 'It's one of the most awe-inspiring achievements in the history of special effects cinema' (2013).

7 The Western reference is apposite, given the normative mythologisation of the male astronaut as a calm and collected frontiersman (Opt, 1996, p. 43).

${ }^{8}$ From Shree 420 (Raj Kapoor, 1955).

${ }^{9}$ Kowalski's dismissal of Shariff's song and dance celebration bears the trace of American culture's long-standing association of India and Indian men with effeminacy (see Rotter, 1994, p. 522).
}

\section{Bibliography}

Christine Battersby (2007) The Sublime, Terror and Human Difference (London: Routledge).

André Bazin (2009) What is Cinema? translated by Timothy Barnard (Montreal: Caboose).

Bruce Bennett (2013) 'The normativity of 3D : cinematic journeys, 'imperial visuality', and unchained cameras', Jump Cut: A Review of Contemporary Media, 55, http://ejumpcut.org/archive/jc55.2013/Bennett-3D/index.html, date accessed 24 May 2016.

Giuliano Bruno (2002) Atlas of Emotions: Journeys in Art, Architecture and Film (London: Verso).

Scott Bukatman (2003) Matters of Gravity: Special Effects and Supermen in the 20th Century (Durham, NC \& London: Duke University Press). 
Justin Chang (2013) 'Venice Film Review: Gravity', Variety, 28 August, http://variety.com/2013/film/reviews/gravity-review-venice-film-festival-1200589689/, date accessed 26 February 2017.

Richard Corliss (2013) 'Gravity: The Glory of Cinema’s Future', TIME Magazine, 3 October, http://entertainment.time.com/2013/10/03/gravity-the-glory-of-cinemas-future/, date accessed 1 January 2016.

Thomas Elsaesser (2013) 'The "Return" of 3-D: On Some of the Logics and Genealogies of the Image in the Twenty-First Century', Critical Inquiry, 39 (Winter), 217-46.

Joe Fordham (2014) ‘Gravity: Extra-Vehicular Activity’, Cinefex, 136 (January), 42-75.

André Gaudreault and Philippe Marion (2015) The End of Cinema? A Medium in Crisis in the Digital Age, translated by Timothy Barnard (New York: Columbia University Press).

Tom Gunning (2007) 'Moving Away from the Index: Cinema and the Impression of Reality', Differences: A Journal of Feminist Cultural Studies, 18, 1 (March), 29-52.

Tom Huddleston (2013) 'Gravity', Time Out London, 3 September, https://www.timeout.com/london/film/gravity, date accessed 1 January 2016.

Daniel Morgan (2006) 'Rethinking Bazin: Ontology and Realist Aesthetics', Critical Inquiry, 32, 3 (Spring), 443-81.

Joe Morgenstern (2013) 'Gravity Exerts Cosmic Pull', The Wall Street Journal, 3 October, https://www.wsj.com/articles/SB10001424052702304176904579111881467162864, date accessed 1 
January 2016.

Susan Opt (1996) 'The American Frontier in Film: American Frontier Myth and the Flight of Apollo 13: From News Event to Feature Film', Film \& History 26, 1-4, 40-51.

Andrew J. Rotter (1994) 'Gender relations, foreign relations: The United States and South Asia, 19471964', The Journal of American History 81, 2 (September), 518-42.

A.O. Scott (2013) ‘Between Earth and Heaven', New York Times, 3 October, http://www.nytimes.com/2013/10/04/movies/gravity-stars-sandra-bullock-and-george-clooney.html, date accessed 26 February 2017.

Brad Stevens (2014) 'Faking the Long Take', Sight and Sound, 16 April, http://www.bfi.org.uk/newsopinion/sight-sound-magazine/comment/bradlands/faking-long-take, date accessed 27 February 2017.

Jean-Philippe Tessé (2011) 'La révolution numérique est terminée’, Cahiers du Cinéma, 672, 6-8.

Peter Travers (2013) ‘Gravity’, Rolling Stone, 3 October, http://www.rollingstone.com/movies/reviews/gravity-20131003, date accessed 26 February 2017.

James Udden (2009) 'Child of the Long Take: Alfonso Cuarón's Film Aesthetics in the Shadow of Globalisation', Style, 43, 1 (Spring), 26-44.

Rama Venkatasawmy (2016) 'Crisis in the Digital Visual Effects Industry and Hollywood Cinema', Film International 14, 1 (March), 6-23.

Patricia Yaeger (1989) 'Toward a Female Sublime', in Linda Kauffman (ed.) Gender and Theory: 
Dialogues on Feminist Criticism (Oxford: Blackwell), 191-212. 